\title{
MODELLING THE GENERATIVE POWER OF SERVICE DESIGN PRACTICE THROUGH THE REFINED LANGUAGE OF THE "C-K THEORY"
}

\author{
N. Dragicevic ${ }^{1, \otimes}$, W. B. Lee ${ }^{1}$, E. Tsui ${ }^{1}$ and E. Chew ${ }^{2}$ \\ ${ }^{1}$ The Hong Kong Polytechnic University, Hong Kong, ${ }^{2}$ University of Technology Sydney, Australia \\ $\bigotimes$ nikolina.dragicevic@connect.polyu.hk
}

\begin{abstract}
"C-K theory", a theory of reasoning in design, offers a formal modelling language with the power to describe the unfolding of creativity and the generation of new innovative objects as integral parts of design practice. However, the theory has limited ability to analyze and describe the particulars of design practice when the target area is service. To address this question, the purpose of this paper is to refine the " $\mathrm{C}-\mathrm{K}$ theory" by embedding service relevant constructs and exploring strategies for enhancing the creative engagement resulting in the innovative service concepts.
\end{abstract}

Keywords: C-K design theory, service-oriented design, design practice, framing

\section{Introduction}

The essential feature of design practice is creating what is yet unknown from what is known. A fundamental purpose of the practice of designers, then, is the creation of new knowledge and new "known" products or service. One of the most comprehensive and formally defined accounts of the particulars of design logic - depicting the dynamics between these known and unknown spaces - was provided by Hatchuel and Weil's $(2003,2009)$ "C-K theory." Claiming to be both a design theory and a theory of reasoning in design, "C-K theory" offers a formal modelling language which promises to have both the analytical and descriptive power to depict the unfolding of creativity, learning, and the generation of new innovative objects as integral parts of design practice. Since its conceptualization, "C-K theory" has been used in different design projects in a variety of settings (e.g. Le Masson et al., 2016). Since its focus is on conceptualizing the design of products, we recognize - as we will discuss in this paper - the theory's limited ability to analyse and describe the particulars of design practice when the target area is service.

Through the lens of the service-dominant logic (S-D logic), the prevailing analytical framework for studying service in the contemporary service research, service is conceptualised as value co-creating practices in which the multiplicity of service actors apply their skills and knowledge for the other party or their own benefit (Vargo and Lusch, 2004, 2008, 2016). Value is co-created in use (i.e. valuein-use), through interactions (value-in-interactions), which are primarily social encounters embedded in social (i.e. value-in-social-context) (Edvardsson et al., 2011; Edvardsson and Tronvoll, 2013) or institutional contexts (Vargo and Lusch, 2016).

Congruent with this interactive and practice-based view of service, a few practitioners and scholars suggested to use the term "design for services" instead of service design to emphasise that service is not an end result of design (cf. Kimbell, 2011). As this construct implies, there is a fundamental 
inability of design to imagine and regulate services; instead, the role of design is to provide enabling conditions for desirable interactions to happen.

Due to the limited ability of $\mathrm{C}-\mathrm{K}$ theory to conceptualise these inherent relational and interactive components of service design practice, the following exploratory question emerges:

\section{How can we model service design by extending the formal language of $C$ - $K$ theory and accounting for inherent properties of service practice?}

The main contribution of this paper is that we extend the " $\mathrm{C}-\mathrm{K}$ theory" modelling language to address the problem of conceptualising service design practice while considering how it differs from the practice of product design. Our theoretical discussion (Section 2) shows that service practice relies on human actors' (service providers', customers', and other stakeholders') practice-based and meaning-laden interactions, in which they utilise their diverse knowledge and make sense according to the positions and roles they hold in the service ecosystems, guided by the context-specific rules, meanings, norms and the availability of resources. Consequently, the focus of design becomes to enable service actors to interact and co-create value better by taking into account their diverse positions and roles, and conditions of their interactions. Accordingly, we take this enabling role of service design and relevant constructs into account to extend C-K theory formal language and apply it to model service design (Section 3). Next, we suggest that design practice of framing could be adopted to enhance generativity of service design practice by utilising the refined "C-K theory" and provide an example of application (Section 4). We conclude with a brief discussion and open a gate for future research (Section 5).

\section{Conceptual background}

\subsection{The conceptualisation of service through service-dominant logic}

In this paper, the analytical framework of the service-dominant logic (S-D logic), drawing on earlier research in service marketing and management, articulated by Vargo and Lusch (2004, 2008, 2016), serves as our base to provide an understanding of constructs and relationships relevant to service. The value of S-D logic framework for progressing with service research is well proven in academic research (cf. Breidbach and Maglio, 2016). Moreover, some researchers have suggested that the framework, with its comprehensive articulation of value co-creation, might aid an understanding of what service design is acting on (cf. Wetter-Edman et al., 2014).

Through the S-D logic lens, service is depicted relationally, as an interactive and collaborative effort of the multiplicity of actors who utilise their knowledge, that is, activate or act upon resources with a purpose of satisfying the beneficiary's needs: service providers who offer value propositions, customers who enact these propositions in use (value-in-use), and other partners (such as suppliers). Service is seen as a fundamental basis of economic exchange, whereas products or goods become merely platforms or distribution mechanisms that assist in providing benefit and satisfaction of higherlevel needs through service (Vargo and Lusch, 2004, 2008).

Service as one-to-one interaction has over time evolved to indirect interactions in the large systems composed of many loosely coupled entities, including technology. However, according to S-D logic, this only masks a fundamental direct interaction with a customer. That is, a customer, even when interacting with technological artefacts, is enacting (i.e. putting in use) a value proposition created by the service provider. There is always a co-creational component involved.

A critical concepts emerge, which we will summarize in the bullet points and present in more details in the next paragraphs.

- Service actors $(a 1, a 2, a 3 \ldots)$ - customers, providers and others participating in service practice; value co-creators and resource integrators; ${ }^{1}$

\footnotetext{
${ }^{1} \mathrm{~S}$-D logic has been criticised for focusing on social actors and disregarding the role of technical agency. While seeing a great prospect of further advancing $\mathrm{C}-\mathrm{K}$ theory and service design research by involving nonhuman actors, in this paper, we focus on the role of social actors and acknowledge the role of technology as a resource that human actors interact with or is a medium of their interaction.
} 
- Service practice interactions $(i)$ - actors apply knowledge and skills for the purpose of value co-creation, that is, with a purpose of satisfying their own or other party's needs (n);

- Resources - anything with a potential value that actors can act upon and create value from in service practice (resources are not, they become, cf., Zimmermann, 1951):

- Operant resources (RSOperant) - intangible, knowledge, social networks, culture;

- Operand resources (RSOperand) - tangible, digital and physical artefacts.

Due to its experiential nature, value is contextually contingent as it depends on each actor's subjective interpretation of what is valuable and worthy of engagement. It has been implied in service research that actors' social construction of meanings guiding their use of knowledge and engagement in value co-creating practices can be explained by their sensemaking activities (cf. Edvardsson et al., 2011). ${ }^{2}$

- Sensemaking $(\mathrm{Sm})$ - actors' sensemaking activities explain the processes of determining what is valuable to them as well as their engagement behaviour in service practice;

- Value $(n)$ - refers to beneficiary needs' satisfaction, phenomenologically and experientially determined through actors' sensemaking activities (i.e. their social construction).

The practice and service ecosystem turn, which is currently evolving in the S-D logic studies, posits that service is inherently practice and that value co-creating practices are enabled or constrained by the institutions (structures) - rules, norms and meanings that facilitate configuration and coordination of actors (Vargo and Lusch, 2016). According to practice theories, a field which new developments in SD logic draw from, such as Giddens' structuration theory (1984), three main basic building blocks in understanding service systems as social systems are agency, structure and practice. In connecting micro, agentive perspective with the macro, structural perspective, practice theories provide a research unit for analysing value co-creation as a social practice (cf. Holttinen, 2010):

- Agency $(A g)$ - implies purposeful and intentional nature of actors, their capacity to act;

- Institution or structure $(S)$ - refers to collective rules, norms, meanings and artefacts, coordinating actors' value co-creating practices

- Service practice - consists of actors' interactions, and resources they use, the shared purpose of which is to satisfy beneficiaries' needs

Edvardsson and his colleagues (e.g. Edvardsson et al., 2011; Edvardsson and Tronvoll, 2013) have notably expanded the fundamental aspects of S-D logic theory with the key concepts from social construction theories. Echoing Giddens, Edvardsson et al. (2011, p. 330; emphasis in original) explicate: "Value co-creation necessarily follows social structures and takes place within social systems in which the actors (customers and companies) adopt certain social positions and roles as they interact and reproduce social structures."

Due to the simultaneous influence of both conditions imposed by the structure and the abilities emanating from the agentic powers of actors, human actors are both position-fulfilling and rolemaking beings (see also Edvardsson et al., 2011). In this sense, concepts of position and role are interrelated although heuristically separated for analytical purposes:

- Position ( $1, p 2, p n \ldots$... - defined by the structure $(S)$, describes how actor is situated relative to other actor and is expected to conform to collectively expressed norms, rules and meanings. One's position also decides which resources will be available to actors;

- Role $(r 1, r 2, r n \ldots)$ - emanating from the agency $(A g)$, the role concept describes subjective nature of the actor, his sensemaking abilities that characterise actor's intentions and behaviour.

Value co-creation, hence, involves not only actors' differing knowledge but also their differing value perceptions and different opportunities in terms of access to the resources depending on social positions and their roles in social systems.

\footnotetext{
${ }^{2}$ Compare to the theory of situatedness (cf. Kazakç1, 2013), which advances the view of situated agents and
} their interactions with the environment as being critical to understanding creation. 


\subsection{Service design, $\mathrm{C}-\mathrm{K}$ theory and its limitations}

\subsubsection{Properties of service design}

Congruent with the practice-based, relational and interactive view of service in the S-D logic, the practice of service designers is "an exploratory process that aims to create new kinds of value relation between diverse actors" within a service, which she defines as "socio-material configurations that are relational and temporal as value is constituted in practice" (Kimbell, 2011, p. 41). Such an understanding of service design emphasises the necessity of the involvement and understanding of users and their context through the practice of co-design.

Engaging users is congruent with S-D logic's grounded literature since value co-creation is one of its central characteristics. However, whereas in S-D logic value co-creation implies a broader aspect of collective activity, involving direct and indirect interaction, the notion of co-design is introduced in design literature as the creativity of professional designers and users not trained in design that work together in the design process (Sanders and Stappers, 2008). For example, co-design involves the integration of participants' unique knowledge into service design practice through ethnographic studies, participant observation, interviews, testing the prototypes, ideation and seeking continuous feedback from customers, which makes services collectively constructed design artefacts.

Interactions are particularly critical for service design; Hatchuel (2001) stresses that social relationships are both an essential resource for design and a designable area. He points out that: "Considering social interaction as a designable area is a key feature for economic and organization theory as it directly implies that value creation and creativity are dependent of organizational forms and of the social interactions that shape economic transactions" (2001, p. 7).

Let us consider Hatchuel's (2001, p. 4-8) example of the design problem of how to organise a "nice party". Similar to service design, "nice party" design involves organisers of the party, participants in the party, designers and interactions between them. An initial concept put forward in agreement between organisers of the party and designers of a "nice party" would invoke in different participants involved in co-design different stories of what a nice party means; each person will add some "usual or new qualifying properties" to the "grammar" of what a "nice party" consists of (ibid. p. 8). The design is dependent on the emergent perceptions, needs and knowledge of clients, which are learned (emerge) in the design activity itself involving designers, party organisers and party participants. Such learning generates new problems and concepts, which ultimately lead to the new knowledge objects, a process which involves "cycles of mutual adjustment between specifications and solutions until a final "solution' is reached" (Hatchuel and Weil, 2009, p. 183). Hence, the unexpected designs of what a service is might emerge from the design activity itself, partially due to the dependence of design on the contrasting views, knowledge and choices provided by the actors involved in the process - i.e. novelty is endogenous to the design practice (cf. Hatchuel, 2001).

The authors also acknowledge that design is not only a mode of reasoning; instead, it is a "human collective process shaped by history, culture, and social or organizational norms" (Hatchuel and Weil, 2003 , p. 2). For example, the previous designs and social conventions in the service ecosystem might be restrictive on what kind of solutions might be designed, that is, they might lead to a countable set of solutions. Since all knowledge is created and maintained in social contexts and systems, these social contexts have the power to enable or inhibit actors' value co-creation. This needs to be taken into account in service design practice, congruently with its previously explicated enabling role of service design.

\subsubsection{C-K theory formal framework}

According to the formal framework of the "C-K theory" (Hatchuel and Weil, 2003, 2009), design emerges in the interplay between the two interdependent spaces - knowledge (K) and concept (C) space. $\mathrm{K}$ space contains available knowledge (known propositions) and $\mathrm{C}$ space is where the construction of concepts (undecidable propositions ${ }^{3}$ relative to $\mathrm{K}$ ) occurs. The aim of design practice is to turn these

\footnotetext{
${ }^{3}$ A proposition is undecidable "if it is not possible to prove that this proposition is true or false in $\mathrm{K}$ " (Hatchuel and Weil, 2009, p. 147).
} 
"undecidable propositions" into true propositions in K. K space is a "free parameter", which means that there is no limitation on which knowledge might be used in attempting to construct concepts.

Specific characteristics of the creative and "seemingly chaotic" design practice are captured through four types of operators, through which the spaces are jointly expanded:

- $K$ - $C$ operator - adding or subtracting new properties from $K$ to $C$ through ideation. Alternative concepts can be generated;

- $\quad C$-K operator - turning concepts into new knowledge, seeking for properties in $K$ that could be added or subtracted to $C$ to reach propositions with a logical status in $K$, i.e. that would result in new knowledge object in $K$. Validation methods such as prototypes or mock-ups, consulting an expert, and making tests. One concept can result in multiple new objects;

- $C$-C operator - expansion of $C$ space by refining and reflection upon ideation; one concept generates another concept;

- $\quad K$-K operator - expansion of $K$ space by deduction, experiments, modelling, optimisations and similar.

Once the concept becomes well defined in terms of the properties $(P c 1, P c 2 \ldots P c n)$ that are true in $K$, at this point it is no longer a concept; it becomes new knowledge.

\subsubsection{Limitations and extensions}

Despite the interesting way that the authors resonate about the specificity of social interactions as "both a design resource and a designable area", theory-grounded and practice-based specifics of service, such as the relational nature of service, where the multiplicity of actors collaboratively create value through interactions, so far have not been comprehensively acknowledged in "C-K theory".

We argue that $\mathrm{C}-\mathrm{K}$ theory does not account for the characteristics of service practice as the basis of design activity for several reasons. In sum, the following limitations can be observed in $\mathrm{C}-\mathrm{K}$ theory:

- A designer is given the primary role in design activity and not the other relevant actors, participants of service practice - the necessary distributive nature of design when service is in question have not been acknowledged (cf. Kazakçı, 2013);

- The formal language does not explicitly include interaction space and social construction in CK dynamics;

- The influence of actors' knowledge and learning processes on design activity, and the conditions of design activity remains to a large extent unexplored (cf. Hatchuel and Weil, 2003);

- The notion of using resources in design activity is lacking (cf. Kazakç1, 2013).

During the work on this paper, we found papers building on or discussing in some ways the C-K theory that provided a beneficial context for our reflections on the design activity as applied to service. An exciting alternative conception of the design theory is the CKE theory. Drawing on the Situated Cognition (or situatedness) and taking into account the mutual influence between the designer and the environment, the extension, as a critical difference, introduces the designer's environment, $E$. This inclusion acknowledges that design (including meaning connections) emerges from (and is influenced by) the designer's interaction with the environment.

A further interesting account of design as an interactive and social construction process was provided by Kazakç1 (2013), who discusses the role of designer's interaction with media objects and the communication and negotiation aspects that allows the actor's expertise to be accounted for as a part of broader, distributed design activity. In line with most of Kazakçı's work, in this paper, we adhere to a "design aiding perspective within a constructivist spirit".

\section{Modelling the service design by using the refined language of the "C-K theory"}

As a result of our discussion in the previous section, we modify the formal language of the C-K theory to involve the developed constructs. We focus on a service design practice where service actors are invited to become co-designers who collaboratively envision and generate new service 
concepts (through co-design or value co-creation in designing, Wetter-Edman et al., 2014). It is important to note that, since service providers offer value propositions, they put initial properties into initial concepts, guiding in this way the scope of service design.

To "translate" these observations into the language of the " $\mathrm{C}-\mathrm{K}$ theory", new concepts will be formed relative to $\mathrm{K}$ space containing the propositions which are different (and differently true) for different actors. Accordingly, the choice of properties that will be added to $\mathrm{C}$ depends on which propositions are true for the actors in question $(a 1, a 2, a n \ldots)$ in specific context or structure $(S)$, that is, on their subjective determination of what is valuable (i.e. what might result in their needs $(n)$ being met). In other words, we could say that the K-C disjunctions are sensemaking functions $\left(f_{s m}\right)$ which link knowledge of actors' needs $(K n)$, knowledge about expectations emanating from positions $(\mathrm{Kp})$, knowledge emerging from roles actors' are taking $(\mathrm{Kr})$ and knowledge of available resources (KRSOperant and KRSOperand). Actors make design choices according to their own needs, knowledge and the sense they make from the context surrounding them - e.g. social expectations of how they should behave, technological opportunities that are available to them and choose properties $(P c)$ they will assign to concepts $(C)$ accordingly. Through such sensemaking mechanisms, concepts are socially constructed. The following Equation (1) attempts to depict these ideas:

$$
\mathrm{K}->\mathrm{C}=f S m(K n, P c, K r v K p, \text { KRSOperant } v \text { KRSOperant })
$$

Interactions are the main source of the emergence of new concepts. Hence, the proposed $\mathrm{K}->\mathrm{C}$ function will be conducted by the multiplicity of service actors, suggesting the need for the involvement of the multiple K spaces, such as customers', service providers' and designers' (Figure 1).

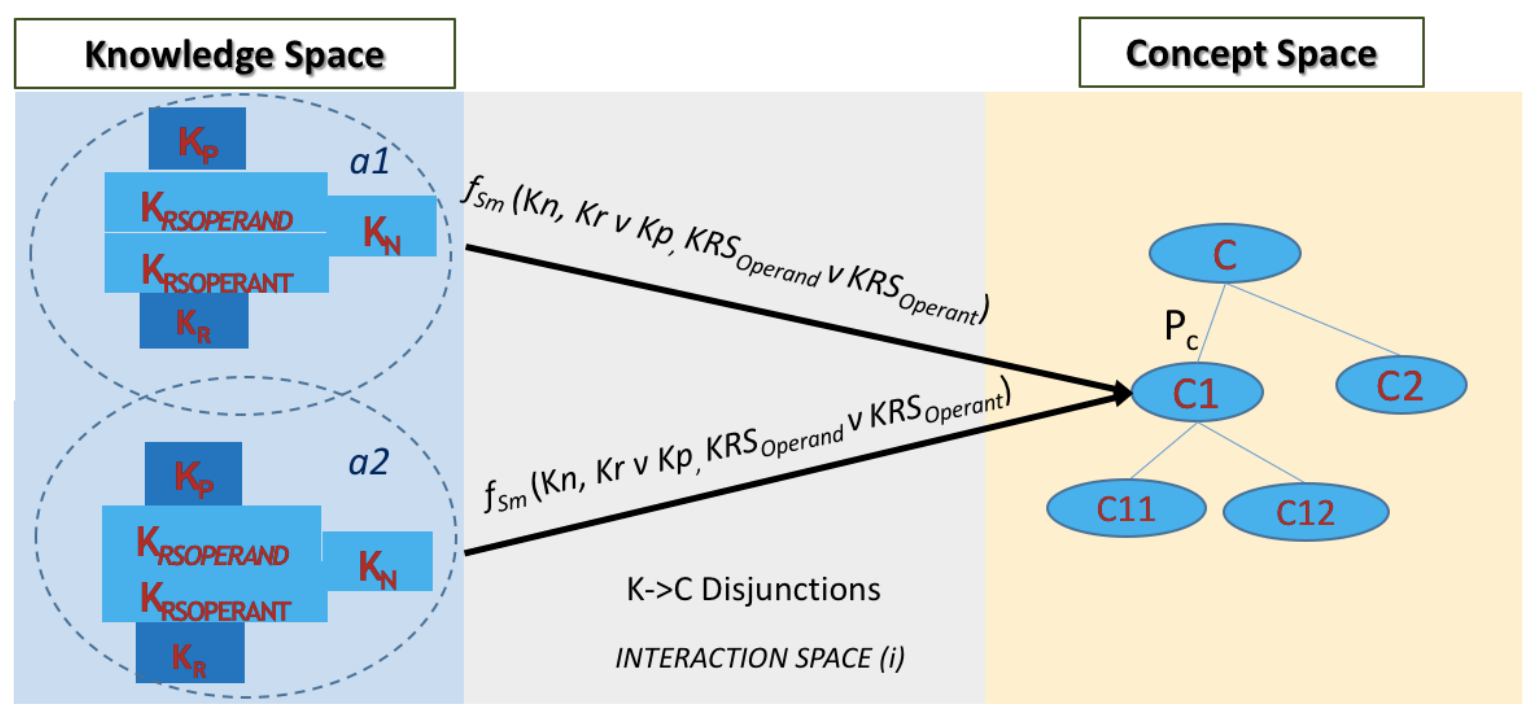

Figure 1. Redefining the " $\mathrm{C}-\mathrm{K}$ theory" for design for service

To ensure that the added properties are feasible or whether they indeed satisfy beneficiaries' needs, they need to be tested $(C-K a I ; C-K a 2 ; C-K a n . .$.$) . A multiplicity of perspectives are involved in the$ service value co-creation, whereas the beneficiary is the one who ultimately determines what is valuable.

It can be assumed that due to their different needs $(n)$, positions $(p)$, roles $(r)$ and the different availability and use of resources, actors will have different logics. Hence, service concepts are emergent phenomena resulting both from composition and compilation processes (Kozlowski et al., 2013). Whereas composition reflects actors' shared, homogenous value perceptions under the influence of collective meanings and polices in the service ecosystem, compilation reflects actors' diverse knowledge and value perceptions (Figure 2). The following Equation (2) might represent the idea:

$\mathrm{C}=f($ Knemergent, Kremergent $v$ Kpemergent, KRSoperantemergent $v$ KRSoperandemergent $)$ 


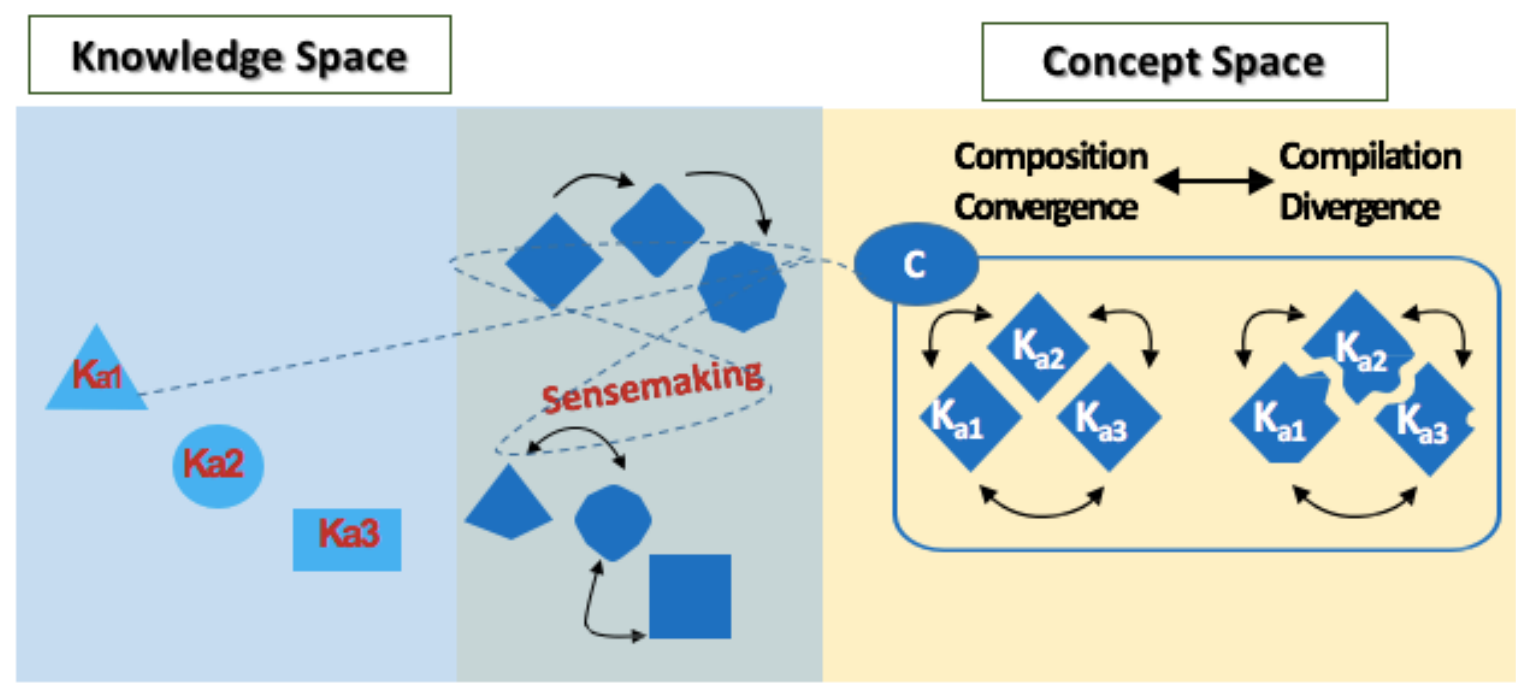

Figure 2. Compositional and compilation emergence

\section{Framing as a strategy for enhancing the generativity of service design practice}

\subsection{Breaking the rule of knowledge structures as a source of generativity}

Based on the expanded view of design theory, which considers the particulars of service practice, the following question emerges: How could we utilize this new understanding to theoretically explain and practically enhance the generativity of service design?

Le Masson et al. (2016) suggests that design generativity is characterised both by knowledge creation and reordering of knowledge structures induced by the design. Taking the education example, they note that 'unfixing' exercises, help the students to break a rule governing the knowledge space and avoid assimilating the object with a typical form. Building on similar propositions, Brun et al. (2018) report the use of non-verbal devices (such as pictures) as a way of mobilising more flexible knowledge structures and stimulating creative, generative designs. The authors nicely express the core idea: "the new knowledge input does not directly impact the C-space: it will first impact the $\mathrm{K}$-space, create new design rules, and allow opening new conceptual paths, which could not have been reached with the previous knowledge structure" (p. 1803). In both mentioned studies, however, the emphasis was not put on the specifics of design for service.

In this paper, we consider ways of "breaking the rule of knowledge space" by paying particular attention to the formulation of initial design briefs, regarded as an important step in the design activity in " $\mathrm{C}-\mathrm{K}$ theory" and other design literature. Hatchuel (2001) and Hatchuel and Weil (2003, 2009) note that design reasoning starts with design briefs, which are necessarily characterised by the equivocal, incomplete, fuzzy or paradoxical formulation of a design task. In other words, the initial formulation of a design specification allows for and triggers unexpected expansion by indicating some ambiguous group of properties of an artefact, but leaving the artefact to be partially unknown and its construction undecided with available knowledge. Design logic - by intentional initial paradoxical or fuzzy formulation of a problem - triggers the design process and frees the designer from predefined steps and categories. The design brief can be, for example, expressed through a short sentence which contains rich semantic possibilities. In the next section, we provide a short discussion of how design briefs could be intentionally designed by taking into account the common design practice of framing.

\subsection{The proposed structure of "frames" to enhance generativity}

A common design practice of framing, well know from Schön, is suggested to be adopted to enhance generativity of service design practice by utilising the refined " $\mathrm{C}-\mathrm{K}$ theory". Based on the abductive reasoning, framing and frame creation is a practice of identifying (often through qualitative research 
involving service actors) common patterns of value co-creation scenarios in the service context at hand which have limitations with their "working principle", and, then, suggesting a new way of looking at the situation (a new frame) and a set of activities that would enable value co-creating interaction of actors to occur in a better way (e.g. Dorst, 2011, 2015).

We propose that a frame corresponds to an initial concept $(\mathrm{Co})$ or a design brief, which contains intentionally developed elements to facilitate sensemaking (social construction of meanings), while at the same time it induces the change in K spaces by providing new "working principle" or rules and conditions of interactions that support actors' creative engagement with the purpose of developing service concepts. This argument is congruent with the enabling view on design, i.e. design for service (cf. Kimbel, 2011), explicated above.

In particular, based on the refined language of " $\mathrm{C}-\mathrm{K}$ theory", we suggest the effectiveness of "frames" can be enhanced by including a set of cues (Figure 3): a design challenge with a new, reframed perception on the situation; new conditions of interactions created by taking into account actors' positions and roles; actors' needs as the aspired value that should be attained by design; expansive examples of resources relevant to the situation at hand that modify its identity by adding relevant and unexpected attributes (such as examples of creative use of operand and operant resources, augmented with digital components). By embedding these "cues", a "frame" creates a point of reference against which a direction of what should be designed is set. It limits the number of ways in which actors could use their knowledge and how the design could proceed, however, it still provides leeway in the possibilities of what will be created.

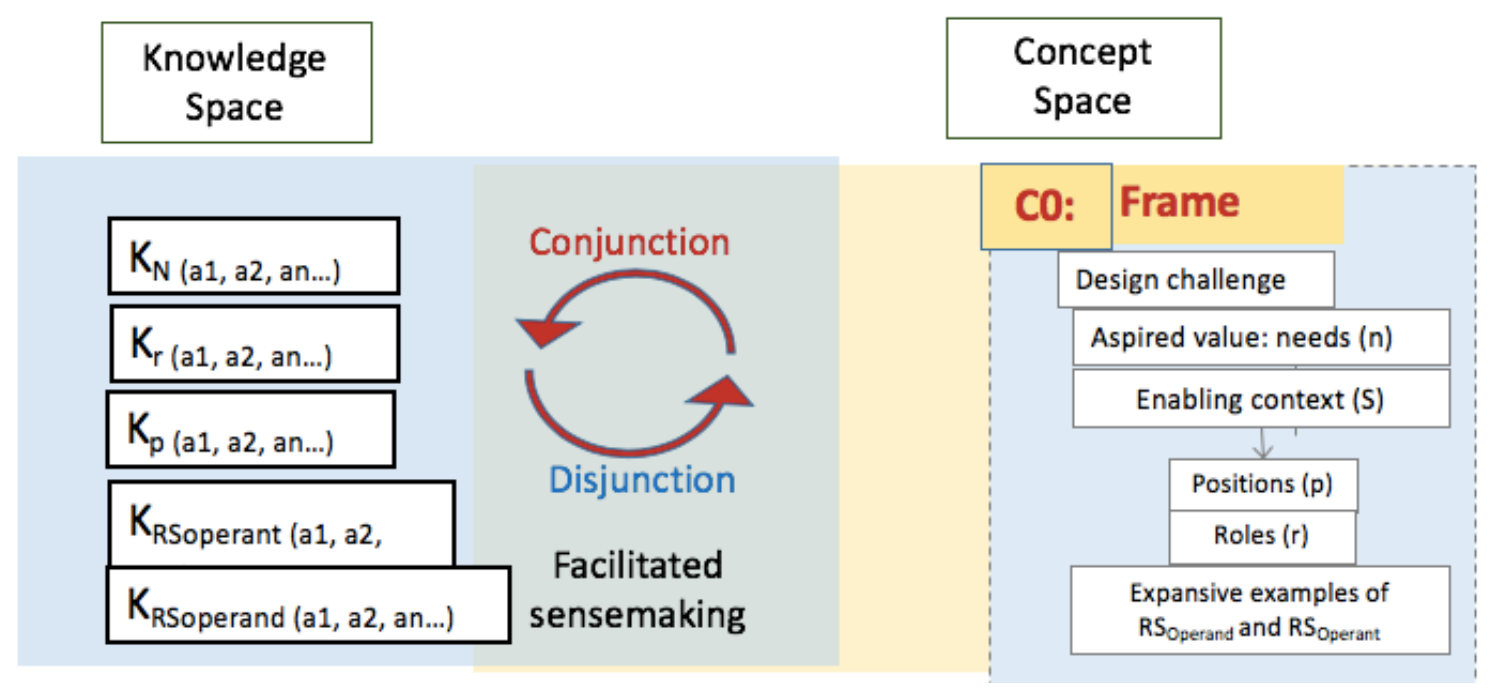

Figure 3. The FRAME in C-K spaces

\subsection{Example of application}

Let us illustrate these propositions with a recent project that we have conducted in an energy company in Hong Kong. A smart service is a type of service emerged due to the advances in digital technologies, relying on smart objects (e.g. smart machines or smart meters), gadgets, digital platforms and other smart technologies (e.g. Wünderlich et al., 2015). The project focused on creating smart service concepts that would enable Hong Kong in becoming a smart city by challenging the meaning of "smart". In particular, we have conducted a workshop in which we have challenged the prevailing, merely technology-centred view on what is smart service by creating a design brief (an initial concept (Co)) or frame titled "smarter service" with a design challenge framed as follows:

How might we design innovative smart service concepts in the energy domain through the use of technologies and active citizen engagement that would support the development of Hong Kong as a "smarter city"?

The frame had embedded cues (according to the proposition above), which were narrated or provided via templates to actors, such as expansive examples of technology resources (RSOperant and 
RSOperand) (e.g. crowdfunding platforms, open innovation models), a structure for co-creation of participating actors - separated into teams of customers/citizens and service providers, and aspired value - needs $(n)$ that were elicited at the meetings and workshops conducted prior to the experimental workshop. To create enabling conditions for actors' engagement, we have utilised knowledge of actors' positions $(p)$ and roles $(r)$ and utilised scenario-based ${ }^{4}$ service design activities that allowed the two teams to brainstorm ideas and develop concepts $(\mathrm{K}>\mathrm{C})$ and to interact and provide continuous feedback to each other's ideas $(\mathrm{C}>\mathrm{K})$.

The results of our experiment showed that the implementation of the frame allowed participants to express their subjective views on what "smarter service" is (through their sensemaking $\mathrm{Sm}$ ) and how it can address their unique needs, in such a way that it provided an enabling, stimulating space for them to be an 'expert of their experience' (cf. Sanders and Stappers, 2008). Since the suggested frame was subject to the sensemaking of each actor, it was experienced differently by each actor - Sal, Sa2, San. Whereas service providers focused more on utilising the capabilities of the smart metering technology and data analytics, customers/citizens were keener on developing concepts that focus on convenience and healthy living. In synergy, through the feedback loops embedded in the workshop, and consistent with the cues embedded in the frame, they both created smart service concepts that included smart technologies, involved public-private engagement modes and partnerships, and accounted for customer and business needs $(\mathrm{C}-\mathrm{Kal} ; \mathrm{C}-\mathrm{Ka} 2 ; \mathrm{C}$-Kan ...). New concepts formed relative to $\mathrm{K}$ space were based not only on the new semantic re-connections (i.e. semantic disjunctions) but also, to some extent, on disjunctions of meanings that actors assigned to the concept of smart service.

\section{Conclusion}

In this paper, we have discussed how "C-K theory" could be applied to service-oriented design. We have refined the theory by examining actors' designing activities through the perspective of the relevant characteristics of service. Consequently, making salient the influence of structure (i.e. structural effects) on agency and influences of agency (i.e. agentic capacities of actors) on structure - as they are reflected in the practice - were critical for our 'new reading' of the " $\mathrm{C}-\mathrm{K}$ theory". The implication is the following: since service is essentially practice, to innovate service through design, a multiplicity of actors need to be involved and enabling space for their co-creation and expression of subjective meanings has to be created.

Creativity often implies "a resistance to some fixation effect", i.e. a set of known, adopted rules and meanings which are difficult to change (cf. Hatchuel, personal website), including personal dispositions and social rules and meanings. In this paper, we have discussed this problem within the context of combining the common design practice of framing with knowledge of refined " $\mathrm{C}-\mathrm{K}$ theory" to create initial concepts (Co) or design briefs that trigger and guide design. We have argued that conscious construction of frames would allow actors to express their divergent perspectives and to construct concepts with surprising properties that reflect their unique needs.

Further development and application of " $\mathrm{C}-\mathrm{K}$ theory" for service would need to detail all four operators (K-C, C-K, K-K, C-C) and exemplify them through use cases.

\section{Acknowledgements}

The work described in this paper was supported by a grant from the Research Committee of The Hong Kong Polytechnic University under student account code RTZY and K-ZM31.

\section{References}

Breidbach, C.F. and Maglio, P.P. (2016), "Technology-enabled value co-creation: An empirical analysis of actors, resources, and practices”, Industrial Marketing Management, Vol. 56, pp. 73-85. https://doi.org/ 10.1016/j.indmarman.2016.03.011

\footnotetext{
${ }^{4}$ Other examples of tools that are known to support ideation and concept development include games, theatre and bodystorming.
} 
Brun, J., Le Masson, P. and Weil, B. (2018), "Getting inspiration or creating inspiration? The role of knowledge structures in idea generation", DS 92: Proceedings of the DESIGN 2018 15th International Design Conference, Dubrovnik, pp. 1793-1804. https://doi.org/10.21278/idc.2018.0196

Dorst, K. (2011), “The core of 'design thinking' and its application”, Design studies, Vol. 32 No. 6, pp. 521-532. https://doi.org/10.1016/j.destud.2011.07.006

Dorst, K. (2015), Frame innovation: Create new thinking by design, The MIT Press, Cambridge, MA.

Edvardsson, B. and TronVoll, B. (2013), "A new conceptualization of service innovation grounded in S-D logic and service systems", International Journal of Quality and Service Sciences, Vol. 5 No. 1, pp. 19-31. https://doi.org/10.1108/17566691311316220

Edvardsson, B., TronVoll, B. and Gruber, T. (2011), "Expanding understanding of service exchange and value co-creation: a social construction approach", Journal of the Academy of Marketing Science, Vol. 39 No. 2 , pp. 327-339. https://doi.org/10.1007/s11747-010-0200-y

Giddens, A. (1984), The constitution of society: Outline of the theory of structuration, University of California Press, California.

Hatchuel, A. (2001), "Towards Design Theory and expandable rationality: The unfinished program of Herbert Simon”, Journal of management and governance, Vol. 5 No. 3-4, pp. 260-273. https://doi.org/10.1023/ A:1014044305704

Hatchuel, A. and Weil, B. (2003), "A new approach of innovative Design: an introduction to CK theory", DS 31: Proceedings of ICED 03, the 14th International Conference on Engineering Design, Stockholm, pp. 109-110.

Hatchuel, A. and Weil, B. (2009), "CK Design Theory: An Advanced Formulation", Research in Engineering Design, Vol. 19 No. 4, pp. 181-192. https://doi.org/10.1007/s00163-008-0043-4

Holttinen, H. (2010), "Social Practices as Units of Value Creation: Theoretical Underpinnings and Implications", International Journal of Quality and Service Sciences, Vol. 2 No. 1, pp. 95-112. https://doi.org/10.1108/ 17566691011026621

Kazakç1, A.O. (2013), "On the imaginative constructivist nature of design: a theoretical approach", Research in Engineering Design, pp. 127-145. https://doi.org/10.1007/s00163-012-0150-0

Kimbell, L. (2011), "Designing for Service as One Way of Designing Services", International Journal of Design, Vol. 5 No. 2, pp. 41-52, Available: http://www.ijdesign.org/index.php/IJDesign/article/view/938/345

Kozlowski, S.W. et al. (2013), "Advancing multilevel research design: Capturing the dynamics of emergence", Organizational Research Methods, Vol. 16 No. 4, pp. 581-615. https://doi.org/10.1177/1094428113493119

Le Masson, P., Hatchuel, A. and Weil, B. (2016), "Design theory at Bauhaus: teaching 'splitting' knowledge", Research in Engineering Design, Vol. 27 No. 2, pp. 91-115. https://doi.org/10.1007/s00163-015-0206-z

Sanders, E.B.N. and Stappers, P.J. (2008), "Co-creation and the new landscapes of design”, Co-design, pp. 5-18. https://doi.org/10.1080/15710880701875068

Vargo, S.L. and Lusch, R.F. (2004), "Evolving to a new dominant logic for marketing", Journal of marketing, Vol. 68 No. 1, pp. 1-17. https://doi.org/10.1007/s11747-015-0456-3

Vargo, S.L. and Lusch, R.F. (2008), "Service-dominant logic: continuing the evolution", Journal of the Academy of Marketing Science Volume, pp. 1-10. https://doi.org/10.1007/s11747-007-0069-6

Vargo, S.L. and Lusch, R. (2016), "Institutions and axioms: an extension and update of service-dominant logic", Journal of the Academy of Marketing Science, Vol. 44 No. 1, pp. 5-23. https://doi.org/10.1509/jmkg. 68.1.1.24036

Wetter-Edman, K. et al. (2014), "Design for Value Co-Creation: Exploring Synergies Between Design for Service and Service Logic", Service Science, Vol. 6 No. 2, pp. 106-121. https://doi.org/10.1287/serv. 2014.0068

Wünderlich, N.V. et al. (2015), "Futurizing smart service: Implications for service researchers and managers", Journal of Services Marketing, Vol. 29 No. 6, pp. 442-447. https://doi.org/10.1108/JSM-01-2015-0040

Zimmermann, E.W. (1951), World Resources and Industries, Harper and Brothers, New York. 